\title{
BMJ Open Exploring global and country-level barriers to an effective supply of leishmaniasis medicines and diagnostics in eastern Africa: a qualitative study
}

To cite: Sunyoto T, Potet J, den Boer M, et al. Exploring global and country-level barriers to an effective supply of leishmaniasis medicines and diagnostics in eastern Africa: a qualitative study. BMJ Open 2019;9:e029141. doi:10.1136/ bmjopen-2019-029141

- Prepublication history and additional material for this paper are available online. To view these files, please visit the journal online (http://dx.doi. org/10.1136/bmjopen-2019029141).

Received 15 January 2019 Revised 14 March 2019 Accepted 18 April 2019

Check for updates

(C) Author(s) (or their employer(s)) 2019. Re-use permitted under CC BY-NC. No commercial re-use. See rights and permissions. Published by BMJ.

For numbered affiliations see end of article.

Correspondence to Dr Temmy Sunyoto; tsunyoto@itg.be

\section{ABSTRACT}

Objectives To understand stakeholders' perceptions of the access barriers to quality-assured diagnostics and medicines for leishmaniasis in the high-burden region of eastern Africa, and to identify key bottlenecks to improve the supply of commodities for neglected tropical diseases. Design Desk reviews and qualitative in-depth interview study with purposive sampling.

Methods A landscape analysis through literature and desk review was performed. Next, 29 representatives from international organisations, non-governmental agencies, national control programmes from six countries (Ethiopia, Kenya, Somalia, South Sudan, Sudan and Uganda) and manufacturers were interviewed between May and July 2018. Participants were selected purposively and expanded through a snowballing technique.Data analysis was aided by NVivo, applying the framework method as a part of the thematic content analysis approach.

Results The barriers along the visceral leishmaniasis (VL) supply chain were identified as emerging themes, grouped across supply chain activities and health systems component(s). Stakeholders expressed the perception of progress, but bottlenecks persist. VL medicines, in general, lack multisource production capacity and with small market volume, expansion of suppliers is difficult. Procurement is plagued by forecasting difficulties, complex regulatory policies and procedures, and distribution challenges. Weak communication and coordination across different levels resulted in shortages and loss of trust among different actors. Cross-cutting issues spanned from limited political and resource commitment due to low awareness and limited in-country capacity. However, study respondents were optimistic to pursue several remedies, most importantly to build bridges between supply and demand sides through continued dialogue and collaborations. Diagnostics supply has mostly been overlooked; thus, improved investment in this area is needed.

Conclusions Addressing supply barriers in eastern Africa requires consistent, specific efforts at the global and national levels, progressing from current partnerships and agreements. Priority actions include pooled procurement, improved forecast, and increased commitment and resources. Sustainability remains an elusive goal, yet to be integrated into discussions moving forward.
Strengths and limitations of this study

- We synthesised perspectives from stakeholders of the healthcare sector only in the interviews, and manufacturers of visceral leishmaniasis (VL) diagnostic tools were not reached.

- Although important, the country-specific barriers could not be elaborated and quantified in detail as they are beyond the scope of this paper.

- As with any qualitative research, there is a possibility of recall and interviewer bias, but we mitigated this through triangulation with the desk reviews and the authors' experiences.

- The strength of the study is the qualitative method to document the multifactorial barriers of the supply chain of an neglected tropical disease in eastern Africa.

- The comprehensive global and national scope of this study is critical to devise policies and strategies to improve access to VL commodities in eastern Africa.

\section{INTRODUCTION}

Ensuring access to essential commodities for neglected tropical diseases (NTDs) is challenging. Diagnostic and therapeutic options for these conditions are limited due to the insufficient investment in research and development. ${ }^{12}$ Moreover, even when affordable and effective treatments exist, they may not reach the patients in endemic, resource-poor settings. $^{3}$

One of those NTDs is visceral leishmaniasis (VL), or kala-azar, caused by a protozoan parasite of the Leishmania species and transmitted by sandflies. The annual global incidence is 50000-90 000 cases, with $90 \%$ reported from Brazil, India, South Sudan, Sudan, Ethiopia, Kenya and Somalia. ${ }^{4}$ Eastern Africa region showed an increasing VL prevalence in the last few years, contrasting with decreased caseload on the Indian subcontinent where VL elimination as a public health problem is 
Table 1 Overview of current medicines for visceral leishmaniasis

\begin{tabular}{|c|c|c|c|c|}
\hline INN & Manufacturer & Unit, administration & $\begin{array}{l}\text { Price information per } \\
\text { unit* }\end{array}$ & Limitations \\
\hline $\begin{array}{l}\text { Sodium } \\
\text { stibogluconate }\end{array}$ & $\begin{array}{l}\text { Pentostam (Glaxo } \\
\text { Smith Klein) } \\
\text { Generic: Albert } \\
\text { David, India }\end{array}$ & $\begin{array}{l}30 \mathrm{~mL} \text { vial of } \\
100 \mathrm{mg} / \mathrm{mL}, \mathrm{IM} / \mathrm{IV}\end{array}$ & Generic: US\$8.78/vial† & $\begin{array}{l}\text { Toxicity +++ (cardiotoxicity, } \\
\text { pancreatitis, nephrotoxicity/ } \\
\text { hepatotoxicity); painful injections, } \\
\text { prolonged treatment. } \\
\text { Resistance (South-East Asia) }\end{array}$ \\
\hline $\begin{array}{l}\text { Amphotericin B } \\
\text { deoxycholate }\end{array}$ & $\begin{array}{l}\text { Fungizone (Bristol } \\
\text { Meyer Squibb) } \\
\text { Generic companies }\end{array}$ & $50 \mathrm{mg}$ vial, IV & $\begin{array}{l}\text { Variable, US\$ } 7.5 \text { per } \\
50 \mathrm{mg} \text { vial }\end{array}$ & $\begin{array}{l}\text { Nephrotoxicity }+++ \text {, infusion- } \\
\text { related fever, prolonged treatment }\end{array}$ \\
\hline $\begin{array}{l}\text { Liposomal } \\
\text { amphotericin B }\end{array}$ & $\begin{array}{l}\text { AmBisome: Gilead } \\
\text { Sciences }\end{array}$ & $50 \mathrm{mg}$ vial, IV & $\begin{array}{l}\text { WHO-negotiated price: } \\
\text { US } \$ 16.25 \ddagger \\
\text { Market price US } \$ 105-200\end{array}$ & $\begin{array}{l}\text { Slow IV infusion, heat stability: } \\
\text { requires cold chain§ }\end{array}$ \\
\hline Paromomycin & $\begin{array}{l}\text { Generic: Gland } \\
\text { Pharma, India }\end{array}$ & $\begin{array}{l}2 \mathrm{~mL} \text { vial of } 375 \mathrm{mg} / \\
\mathrm{mL}, \mathrm{IM} / \mathrm{IV}\end{array}$ & $\begin{array}{l}\text { WHO-negotiated price: } \\
€ 1.3 / \text { vial }\end{array}$ & $\begin{array}{l}\text { Nephrotoxicity/hepatotoxicity, } \\
\text { ototoxicity }\end{array}$ \\
\hline
\end{tabular}

*Data provided during meeting with suppliers during sixth World Congress of Leishmaniasis (May 2017).

†Data from IDA quote.

$\ddagger$ This price was offered in 2014, while in 2016 LAMB donation programme expanded for selected countries in the Indian subcontinent and East Africa.

§According to manufacturers' brochure, stable up to $25^{\circ} \mathrm{C}$ since 2014 .

IPrice only valid for selected governments, United Nations organisations and non-governmental organisations: WHO, PAHO, MSF and DNDi. DNDi,Drugs for Neglected Disease initiative; IDA, International DIspensary Association; IM, intramuscular; INN, International Non-proprietary Name; IV, intravenous; MSF, Médecins Sans Frontières; PAHO, Pan American Health Organization; PO, per oral.

underway. ${ }^{45}$ Outbreaks, compounded by conflicts, population displacement, drought and malnutrition hamper control efforts. ${ }^{6-8}$ VL places a significant economic burden on patients and their families, often the poorest and most marginalised. ${ }^{9}{ }^{10}$ Without treatment, VL is fatal, and as vector or reservoir control is not feasible in this context, early diagnosis and treatment continues to be the cornerstone of VL control strategy. ${ }^{11}$

In this context, reliable supply of VL medicines is vital. However, the therapeutic toolbox is constrained by variable effectiveness in different regions, poor safety profile, stability and $\operatorname{cost}^{12}$ (table 1 ). Since the 1940s until very recently, pentavalent antimonials-sodium stibogluconate (SSG) and meglumine antimoniate (MA)-were the mainstay of treatment. Other drugs are miltefosine (MF; the only oral formulation), paromomycin (PM; a broad-spectrum antibiotic), and amphotericin B deoxycholate and its lipid formulations, including the liposomal amphotericin B (LAMB). Combination regimens have gained prominence over monotherapy, as they reduce resistance risk and treatment duration, for a better safety profile and at a lower cost. ${ }^{13}$ In VL endemic countries in eastern Africa, the first-line treatment regimen is SSG/ PM combination for 17 days, an improvement on the previous 30-day treatment with SSG but still quite long and doubling the painful daily injections. ${ }^{14} 15$ LAMB is reserved for severely ill patients or those with contraindications for SSG/PM, ${ }^{16-18}$ and also for HIV co-infected patients. ${ }^{19}$ The efficacy of treatment varies geographically, for example, the single dose LAMB used as the firstline regimen in the Indian subcontinent is less effective in eastern Africa. ${ }^{20} 21$

The availability of a rapid diagnostic test (RDT) for VL in the mid-2000s, requiring minimal equipment and training, and providing rapid results within $20 \mathrm{~min}$, has made diagnosis simpler at primary healthcare facilities, although roll-out within national programmes were gradual. Other methods such as the direct agglutination test (DAT) and tissue aspiration are more appropriate for use in hospitals. The rK39-antigen-based RDTs are less sensitive in Africa than in Asia, ${ }^{22} 23$ yet their advantages as point-of-care tests make them an essential tool for.the national control programmes.

VL diagnostics and medicines need to be continuously available, affordable and accessible to the health systems and all patients. A functioning supply chain is imperative, but it can be influenced by various factors at multiple levels. ${ }^{24}$ Availability is determined by the manufacturing capacity of the single or few producers. Unfortunately, poor needs' assessment, sub-optimal stock planning and management, and complex procurement procedures often lead to shortages at health facility level. ${ }^{25}$ Forecasting or quantification of needs relies mainly on past consumption data; but the VL caseload can vary considerably from year to year, such as when a VL outbreak occurred in South Sudan in 2012. ${ }^{7}$ In some countries, 
public and private not-for-profit entities, including non-governmental organisations (NGOs) coexist as procurers and, in the absence of coordination, may duplicate efforts. In eastern Africa, VL medicines and diagnostics are mostly provided for free to the patients in the public and non-profit sector yet remains expensive and limit availability for national programmes. Frequent stock-outs deter patients from seeking timely care and frustrate healthcare workers. ${ }^{26} 27$

Despite the increased awareness about the importance of access to essential medicines in general, NTDs, including leishmaniasis, are still neglected. Strengthening of commodity supply chains has often been limited to HIV, tuberculosis, malaria or other priority programmes. ${ }^{28-30}$ For NTDs, studies on availability and access have mainly focused on those that are amenable to mass drug administration, and those mostly rely on large donation programmes. ${ }^{31}{ }^{32}$ In the era of universal health coverage, access to quality-assured medicines and diagnostics for VL must be enhanced, particularly for the eastern Africa region. We conducted this study to document key barriers to sufficient supply of VL diagnostics and medicines, from the perspective of stakeholders at global and national levels from Ethiopia, Kenya, Somalia, South Sudan, Sudan and Uganda.

\section{METHODS}

\section{Analytical framework}

Access refers to people's ability to obtain and use quality health products or technology when they are needed. We interpreted access, not as a single event but as a continuous process involving a series of activities and actors over time. We adopted the access framework from Frost and Reich $^{33} 34$ which encompasses four key elements (affordability, availability, quality and adoption), and three overarching elements from the health system's perspective (coordination, financing and legislation). ${ }^{35}$ We defined the supply chain as an ecosystem of organisations, people, technology, activities, information and resources that come together to ensure the most efficient delivery of the product from the point where it is manufactured to the end user, the patient. ${ }^{36}$ We broke down the key steps of the supply chain into six main activities (figure 1).

\section{Study design}

The study consisted of two parts: first a policy analysis of the access landscape at global and country level through desk reviews, and second, mapping of supply barriers through in-depth interviews (IDIs) of key stakeholders at the global and national levels. The literature covered both peer-reviewed and grey literature, in the field of VL supply in eastern Africa (ie, Ethiopia, Kenya, South Sudan, Somalia, Sudan and Uganda). The online sources included PubMed, Web of Science, Eldis, Google and Google Scholar. Grey literature included national policy documents or guidelines, WHO published information, reports and meeting records. The desk review was conducted between November 2017 until April 2018.

For the second part, we employed a qualitative research method through IDIs with individual key informants. Purposive sampling was chosen to ensure maximum depth and variation of information and was furthered with snowball sampling. Participants for IDIs consisted of representatives of three categories: (1) global stakeholders, that is, multilateral organisations, non-governmental organizations (NGOs), donors and procurement or distribution agencies; (2) manufacturers of leishmaniasis medicines and (3) country stakeholders, consisting of civil servants of the Ministry of Health $(\mathrm{MoH})$, national programmes or in-country implementing partners.

The purpose of the study was introduced to all participants by email or phone. Informed consent was obtained from all participants before the interviews began. The principal investigator (TS), who is trained in qualitative research methodology, conducted all IDIs. Interviews were done face-to-face, by telephone or Skype and conversations were, after the consent, recorded on a digital voice recorder. Semistructured topic guides were piloted and then used to guide the IDIs, and additional items were included as data collection progressed (see the online supplementary information $1 \mathrm{a}, \mathrm{b})$. The IDI lasted on average $60 \mathrm{~min}$ (range: $45-90 \mathrm{~min}$ ). Data collection continued until saturation was reached and no new

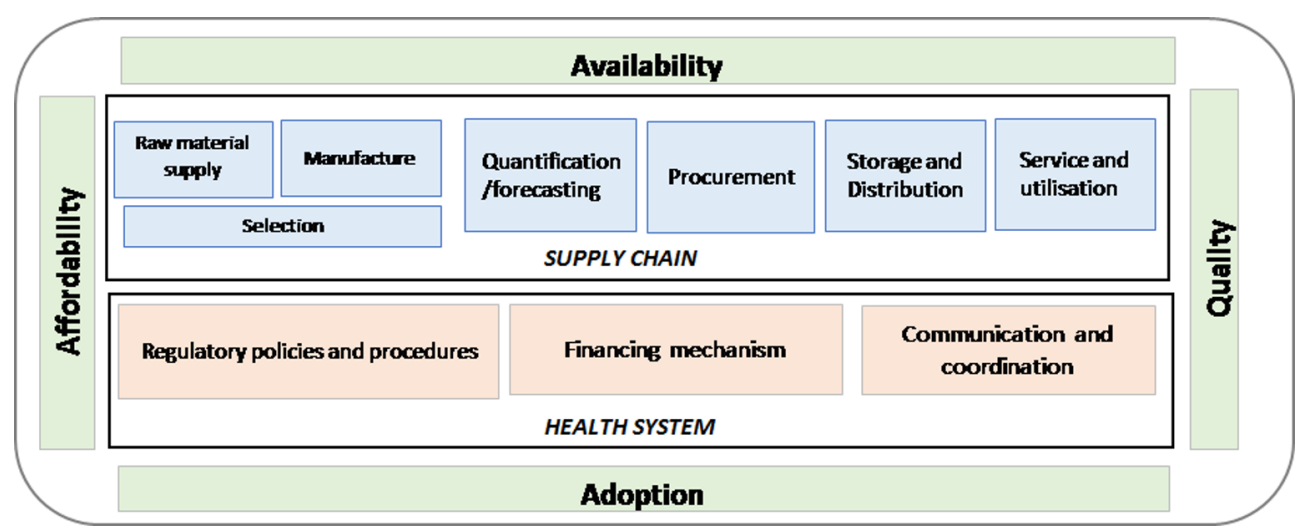

Figure 1 Conceptual framework of supply chain within access. 
information emerged. All interviews were conducted in English.

\section{Data management}

Recordings from the interviews were transcribed verbatim by a professional transcriber, with quality supervision by TS. TS and JP independently reviewed and analysed the data using the framework method analysis. ${ }^{37}$ This method is used to organise and manage research through the process of summarisation, resulting in a robust and flexible matrix output which allows the researcher to analyse data both by case and theme. ${ }^{38}$ Following the thematic content analysis approach, ${ }^{39}{ }^{40}$ we identified themes through careful reading and re-reading of the data, and the emerging patterns and themes became the categories for analysis. Using the analytical framework displayed in figure 1, we applied a broad deductive approach using pre-defined codes but allowed some open coding to ensure the essential aspects of the data were not missed. We classified, compared and charted the data into a framework matrix (see the online supplementary information 2). The charting involved summarising the data by the profile and role of the stakeholder(s) from each transcript, which included the review and comparison of data, across and within matrices. We used NVivo V.12 software (QSR International, Melbourne, Australia) to facilitate data management during analysis.

\section{Ethical statement}

This study is part of a research project for which we obtained ethical approval from the Institutional Review Board of the Institute of Tropical Medicine-Antwerp 1209/17 5IRB/AB/AC/181). Participants in IDIs provided consent and confidentiality were guaranteed. Quoted information was anonymised during the analysis and reporting.

\section{Patient and public involvement}

This study is part of a larger research project on access to care for leishmaniasis in Africa (http:/ / www.euroleish. net), and the research question was informed by the experience of patients' and healthcare workers' who often face the reality that the medicines and diagnostics are not available. Access barriers from patients' perceptions have been published previously, ${ }^{26}$ but there is a critical gap in the barriers from the actors involved in providing care, therefore this stakeholders' study. The results will be shared with the study participants and policy-makers through communication and advocacy actions, in order to increase awareness and improve the effective supply of commodities for this fatal disease.

\section{RESULTS}

Key findings from the desk review are summarised in table 2, while the online supplementary information 3 shows a diagram of the VL pharmaceutical supply system in each country. The online supplementary information
4 provides a list of abbreviations. For the second part, we conducted a total of 29 IDIs (table 3). Respondents from the country represented Ethiopia, Kenya, Somalia, South Sudan, Sudan and Uganda.

\section{Reported barriers along the supply chain in VL endemic countries in eastern Africa}

Respondents opinions on the barriers within the supply chain activities framework (figure 1), which apply to both VL medicines and diagnostics unless stated otherwise, were documented.

\section{Barriers in manufacturing VL medicines and diagnostics}

The manufacturers of the finished pharmaceutical products (VL medicines in table 1) depend on outside suppliers of active pharmaceutical ingredients (API) (eg, Gland Pharma has to order API from Italy to make PM, and Knight's source of API is in Switzerland), which can affect the lead delivery time. In some cases, the same company that produces the finished product may also produce the API (eg, Albert David for SSG), reducing the delay. However, the manufacturers explained that lines of production have been designed to produce only certain quantities (ie, one batch, eg, 8000 vials for SSG, 70000 vials for PM and 200000 capsules for MF). This minimum order quantity may pose difficulties for procurers and prolong the delivery time.

\section{"Access for us is volumes and forecasts. If we do not have a proper forecast, it is hard to schedule productions. It takes a lead time in between the moment we intend to produce, and the moment it is available for shipment. This time cannot be shortened with different requirements regarding the quality of the API, the active ingredient, and the rest of the chain." \\ (IDI, manufacturer)}

The development of all current VL medicines (AmBisome, SSG, PM and MF) was based on partnerships between industry and the public sector, at least for part of their development history. Although this has created a certain 'familiarity' between stakeholders and each manufacturer, it was felt insufficient to bridge the gap between the commercial mindset and public health needs. The diversity in company profiles and policies resulted in different 'access' strategies: donation in the case of AmBisome or tiered pricing in the case of MF. Respondents expressed concern that the shrinking market due to the declining caseload in South Asia may lead companies to halt production. VL medicines constitute a relatively small segment in the companies' portfolio, and without market incentives, ceasing production is a plausible scenario. Nevertheless, all industry representatives expressed their commitment to continue producing VL medicines, as an expression of corporate social responsibility or from an altruistic motive. Similarly, for diagnostic tools, respondents considered the limited number of sources for purchase of rK39 RDT to be especially problematic given that these RDTs are in the front line of every country's diagnostic algorithm. 

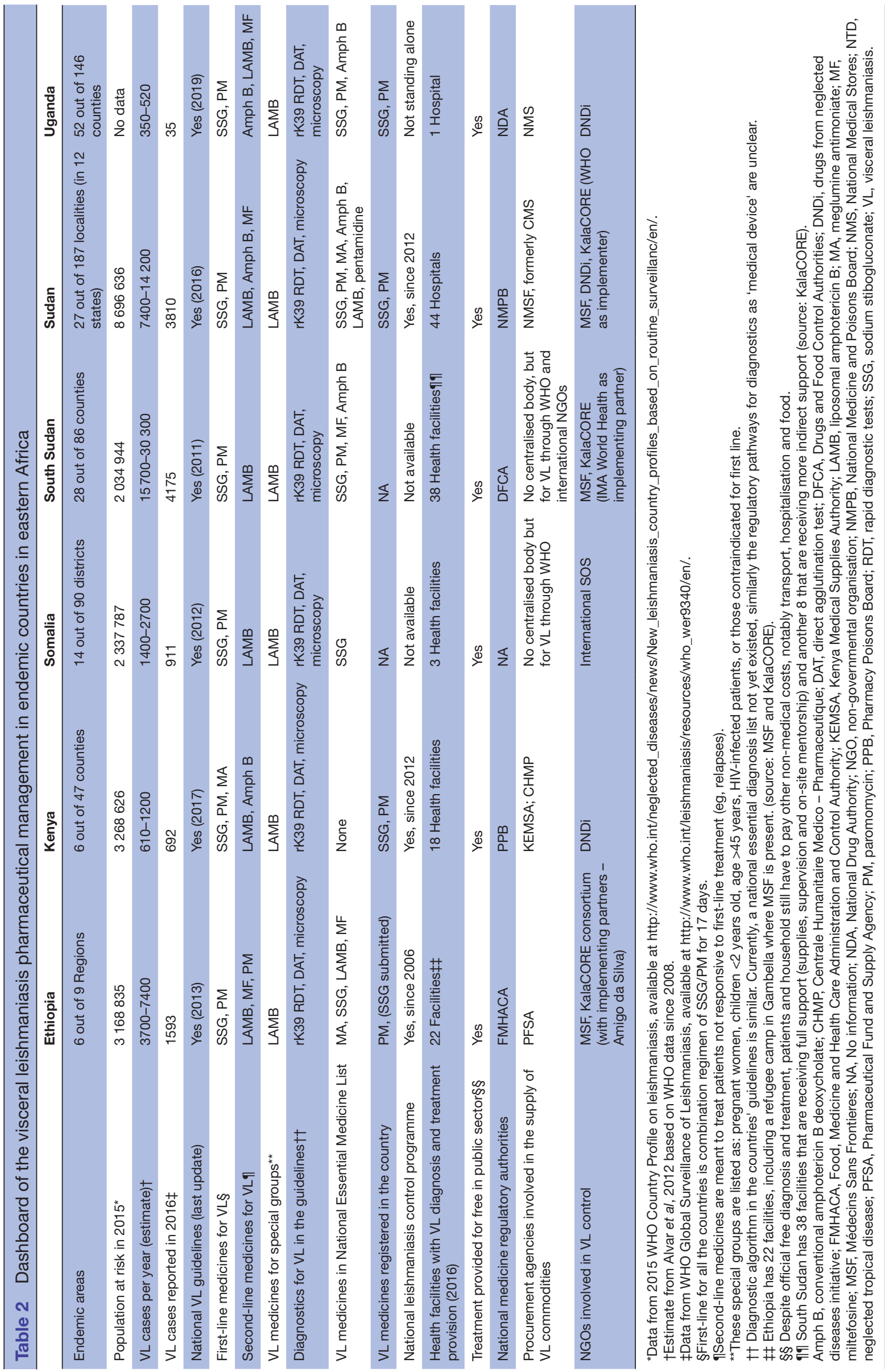


\begin{tabular}{llc}
\hline Table 3 & Overview of resource-persons interviewed \\
\hline Level & Profile & Number \\
\hline Global & Multilateral organisations & 2 \\
& Donor & 2 \\
& NGOs & 4 \\
& Distributor/procurement & 4 \\
& agencies & \\
& Manufacturers & 5 \\
National/country & MoH/Leishmaniasis National & 6 \\
& Control Program & \\
\hline Total & Implementing NGOs & 6 \\
\hline
\end{tabular}

$\mathrm{MoH}$, Ministry of Health; NGO, non-governmental organisations.

\begin{abstract}
"There are stock outs due to unexpected emergencies, but also due to the issue of the one-source suppliers. Either that they could not finish and get the batch in time, the production batch was later than promised and anticipated or that quality issues with a batch. That is the whole problem with the single supplier issue." (IDI, NGOs)
\end{abstract}

\section{Barriers in medicine/diagnostics selection and forecasting}

The list of VL commodities in eastern Africa is short with only a handful of manufacturers. The main repertoire of medicines consists of SSG, PM and AmBisome, whereas $\mathrm{MF}$ has been used only for VL/HIV co-infection (ie, in Ethiopia). The MF+PMcombination is currently undergoing clinical trial (ClinicalTrials.gov NCT03129646). At the global level, the quality-assured sources of these drugs are scarce, and in most cases limited to a single source. For example, AmBisome (Gilead Sciences, Inc, San Dimas, CA) is the only lipid formulation of amphotericin B approved by a Stringent Regulatory Authority (SRA), the current regulatory standard to guarantee product quality. Generic SSG and PM are produced by two Indian companies (Albert David and Gland Pharma), both expressing their willingness to continue producing based on public health needs. For diagnostics, the DAT antigen is only available from two academic centres, ITM in Antwerp, Belgium and the Academic Medical Center of the University of Amsterdam, the Netherlands. For the rK39 RDT, the two widely used brands in eastern Africa are Kalazar Detect (InBios) and IT-Leish (previously DiaMed AG, now BioRad Laboratories). In Sudan, the import of some RDTs was restricted because of economic sanctions by the USA. Respondents expressed the need to improve on the suboptimal performance of rK39 RDTs in eastern Africa, acknowledging that this optimisation will take time, while other tests (rK16, rK28) are still under evaluation.

All stakeholders concurred that consolidating demand, in the form of forecasting, is the critical issue to ensure availability.
"The forecasting is done by people, not by the machine." (IDI, Multilateral organisation)

"Even the historical data is difficult to use in a situation like kala-azar." (IDI, Distributor)

Data on past consumption determine the quantities being ordered at the health facility level, with a centralised buffer stock deemed necessary to compensate for the fluctuating caseload. In the context of health system devolution such as in Kenya, coordination for a common country forecast is even more challenging.

\section{"The health centre may see only 10 people because after 2 weeks of rupture in drugs, nobody came. But the next month they only ordered the same... inability to have a constant supply also limits their knowledge on the number of cases, because they don't record the case that they weren't able to treat." (IDI, NGO South Sudan)}

Furthermore, reporting quality is considered as not yet satisfactory (eg, due to delay, lack of dedicated staff, weak stock management or unreliable data), despite increase support on surveillance and effective communication at different levels. A 'push' mechanism-sending medicines to hard-to-reach facilities or in anticipation of cut-off access in the rainy season-is done pragmatically, for example in Sudan and South Sudan.

From the manufacturers' perspective, the forecasted demand is welcome information, yet results in frustration when not all predictions are translated into real orders. A 'single entity' holding all actors in the supply chain accountable would be welcome.

\section{Barriers in VL medicine/diagnostic procurement process}

In all countries, a vertical commodity supply system for VL exists, that is parallel to and separate from the procurement and supply of essential medicines. Purchasers from the public sector and not-for-profit NGOs involved in VL control can place an order directly to the manufacturer or a procurement agency (see figure 2). A private market for these commodities is non-existent. The centralisation of orders can take place, meaning a 'leading' actor keeps an overview of needs, orders and stock at the country or regional level, but such coordination mechanisms depend on specific funding contexts.

\section{"Yes, we buy our own drugs and diagnostics, not to be de- pendent on vulnerable supply lines from the national system or from others." (IDI, Country NGO)}

Centralised supply management by WHO is currently in place for the AmBisome donation programme in the six countries. WHO also manages the procurement of SSG and PM in all except Uganda (where this is taken care of by Drugs forNeglected Diseases initiative (DNDi)). WHO supplies VL commodities to all NGOs working with VL in Kenya, Somalia, and South Sudan, except Médecins Sans Frontières (MSF) and DND $i$. The latter organisations procure independently for their projects in Ethiopia, Sudan, Kenya and Uganda, as there are no 


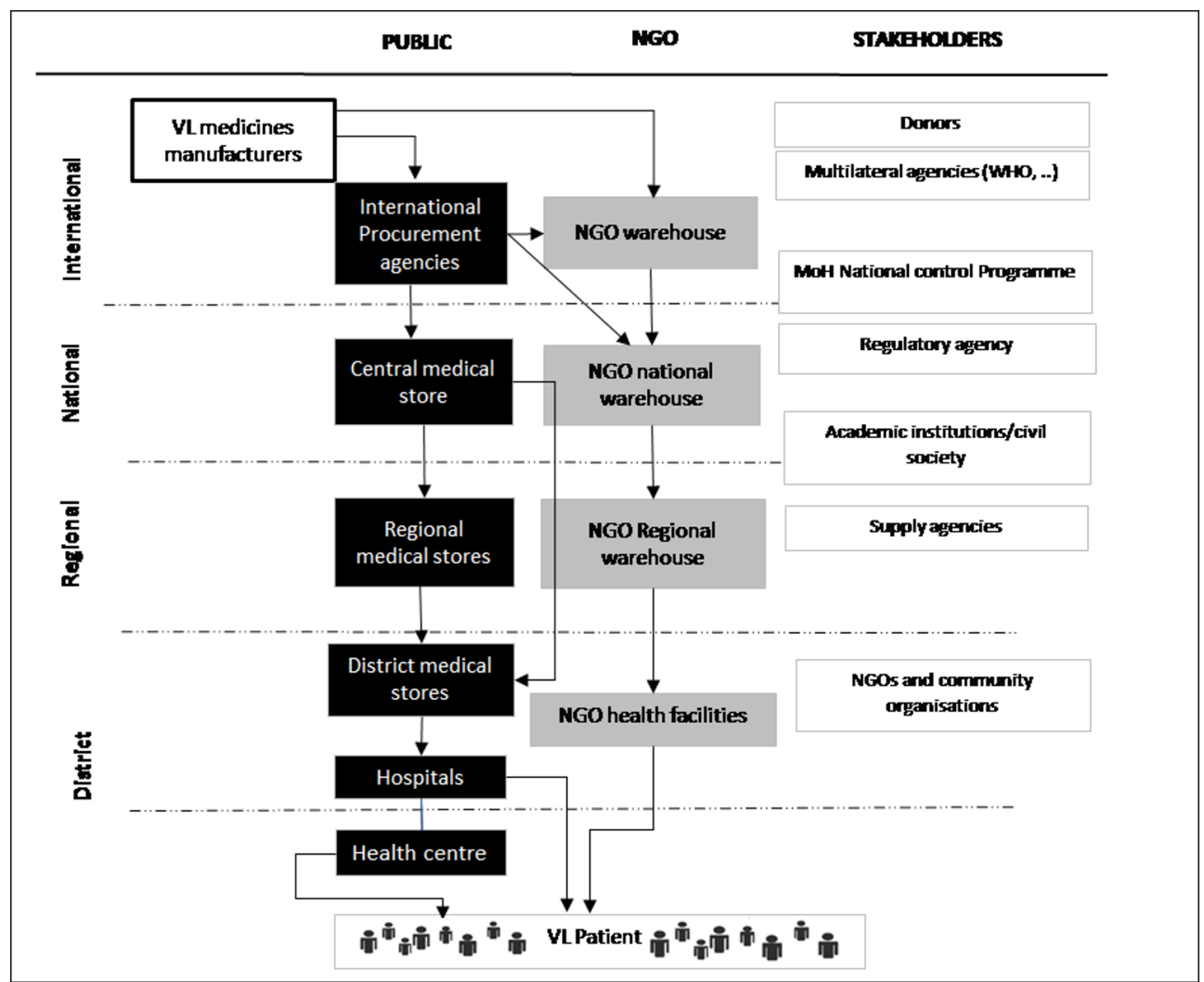

Figure 2 Procurement and distribution network of leishmaniasis diagnostics and medicines in the eastern Africa region. NGO, non-governmental organisation; VL, visceral leishmaniasis.

other NGOs involved in VL. A decentralised process was tried in 2017, in which WHO country offices, in coordination with National Control Programmes, managed the procurement. However, long delays ensued due to lack of awareness about the long lead time for SSG and PM delivery, especially as the orders were not submitted in time and the volumes were too small. Many respondents perceived the procurement process as frustrating:

"They are not able to change the situation very quickly; they say no, the drugs are in customs or waiting for customs clearance. Sometimes orders are blocked on the path from the health centre to the regional, or federal level. It is this procedure and the fact that the kala-azar drugs are not part of the normal procurement cycle." (IDI, donor)

VL diagnostics are usually procured together with the medicines, though national programmes or implementation agencies face more difficulties in identifying the right channels to contact the manufacturers. Certain specific issues were raised by the participants, such as the short shelf life of the RDT, which had impeded importation, as procedures require a certain remaining shelf life. Different country regulations regarding diagnostics could obstruct receiving a donation when there was a shortage, such as was the case in 2017/2018 in South Sudan. Registration of diagnostic tests in-country is often problematic, and some companies impose a minimum purchase order and require registration as a buyer.
Barriers to the distribution of $\mathrm{VL}$ medicines/diagnostics

Distribution and delivery of VL medicines are generally done separately through a vertical programme in the public sector (figure 2), without 'integration' into the general supply of essential medicines (Central Medical Store or equivalent mechanisms). However, a certain degree of logistic integration takes place, for example, distribution of VL commodities follows the national supply agency schedule in certain states in Sudan. Health-facility level stock-outs occur regularly and require impromptu solutions, for example, the dispatch from other VL centres nearby or from central facilities. Long lead or delivery times are reported frequently, though reasons given for this ranged from bureaucracy or lack of communication, for example, lower levels not knowing about existing stock at the regional level, or vice versa. Shortages have invariably been reported, with the notable example the big stock-out during the 2012-2014 outbreak in South Sudan.

We do not get forward planning and predictions, and suddenly everybody starts saying: Oh, you are out of stock!(IDI, MoH)

Respondents considered the lack of stable funding for the management of medium and long-term stocks of VL medicines as the main factor that negatively affects availability. These barriers inevitably also applied to diagnostic devices, especially with regards to cold chain 
requirements which complicate adherence to good distribution practices. Logistic challenges such as the rainy season, lack of roads and transport delays are common, especially in South Sudan where the infrastructure is extremely limited. The cost of distribution is high if the only options are small aircraft or airdrops. Respondents describe the management of transportation and storage as challenging, especially in tropical contexts where the temperature often exceeds $25^{\circ} \mathrm{C}$ (the limit for AmBisome) or $30^{\circ} \mathrm{C}$, for RDTs.

\section{Reported barriers in the health system affecting the VL commodities supply chain}

Legislation: barriers in regulatory procedures and policies for VL medicines and diagnostics

The regulatory requirements for granting a marketing authorisation (or registration) to medicines varies from country to country, and not all VL medicines are yet registered where they are used. Also, the registration process can be inefficient; for instance, in Sudan and Ethiopia, the registration process for SSG and PM took years, and SSG registration is still pending in Ethiopia. Medicine registration involves a complex regulatory pathway and is the jurisdiction of the national medicines regulatory authorities (NMRAs). The manufacturers are responsible for submitting the registration dossier to the NMRAs; unfortunately, there are little or no commercial incentives to do so when there is no profitable private market.

\section{"Registration comes at a cost, so if you do not have the commercial value, then you wonder why you want to in- vest that time and money into that." (IDI, Multilateral organisation) \\ "If the private market, for some reason, we are providing a decent number that could justify registration then we would look into it. But the truth is that that is not the case any- where, because this disease is mainly in countries with low income." (IDI, Manufacturer)}

The registration process may be costly and labour-intensive, further lessening the appeal. Technical and financial support from international agencies such as the IDA Foundation and DND $i$ has been crucial in registering SSG and PM in Sudan and Ethiopia.

In reality, respondents reported that VL medicines that are listed in a country's Essential Medicine List and recommended in the national guidelines could be granted a special import authorisation, despite not (yet) being formally registered. In the long term, the respondents agree that registration is crucial, as it is the best way to guarantee that the quality of the product has been duly evaluated and approved by the National Regulatory Authority. Harmonisation of regulations across NMRAs in different countries is desirable as harmonised inspections and registration dossiers would mean a significantly reduced cost for meeting registration requirements. Different regulations in labelling and quality requirements had complicated importation in the past. The regulatory pathways for RDTs, which some consider as 'medical devices', are an area that is currently being overlooked, with unclear procedures on registration and utilisation. Some respondents raised the issue of the lack of a quality-assurance mechanism.

"Some countries tend to overshoot with the regulations... you have to balance the registrations against what is needed, there's a gap, and they [countries] don't have the capacity. Leishmaniasis is a very limited disease in fact, so it is easy to ask all of these requirements, but there's a mismatch about the time frame and the cost of the registration and what is immediately needed." (IDI, NGO)

Ensuring the quality of VL medicines was deemed to be a priority by the respondents. Currently, only AmBisome and Impavido (MF) have been authorised by an SRA, while neither generic SSG nor PM are prequalified by any SRA nor by the WHO Prequalification Programme (WHO PQP). In 2016, both generic manufacturers of SSG and PM obtained time-limited positive advice from WHO's Expert Review Panel (https:/ / extranet.who.int/prequal/ sites/default/files/documents/73_ERP_Feb2019.pdf), which is a mechanism designed to help identify quality products to meet urgent demands, based on a careful risk assessment. However, stringent approval or prequalification should be aimed for in the long term. Respondents stated that the limited awareness of these processes, including the recent WHO Collaborative Registration Process across various stakeholders, is a barrier. The respondents expressed the need for these mechanisms to be more widely shared, advertised and communicated. More efforts to engage with VL medicines manufacturers, for example, in responding to invitations for expression of interest on the WHO PQP website, are recommended by study respondents. SSG and PM were included in the 2015 call, and LAMB and MF were added in 2017.

\section{Barriers to the financing of VL supplies}

All respondents stressed the fact that VL is still neglected at the country level, despite the creation of national working groups or task forces, such as in Kenya or Sudan. Political commitment beyond MoH lacks in all the VL endemic countries, especially when it comes to financing or budget allocation. The responsibility of the $\mathrm{MoH}$ for these NTDs is not fully realised when external partners bring in the medicines and diagnostics. None of the countries is currently procuring VL commodities by themselves independently.

Moreover, the respondents pointed out that as VL usually clusters in a few and generally remote regions of a country, policy-makers in the capital lack awareness of the disease. Clinical and diagnostic skills are equally concentrated in towns and not freely available in the VL-affected areas. Capacity strengthening is jeopardised by the high turnover of health staff, both in clinical duties and in control programmes. For most of the respondents, the unsustainable funding mechanisms, even for the medium term, limits the reach and scope of VL control 
Table 4 Price per visceral leishmaniasis treatment per course

\begin{tabular}{|c|c|c|}
\hline $\begin{array}{l}\text { Current treatment regimen used in eastern } \\
\text { Africa }\end{array}$ & Treatment duration (days) & $\begin{array}{l}\text { Medicine cost in US\$* for } 35 \mathrm{~kg} \\
\text { patientๆ }\end{array}$ \\
\hline SSG $20 \mathrm{mg} / \mathrm{kg} /$ day + PM $15 \mathrm{mg} / \mathrm{kg} /$ day & 17 & $42-51$ \\
\hline SSG $20 \mathrm{mg} / \mathrm{kg} /$ day $\dagger$ & $28-30$ & 61 \\
\hline PM 15 mg/kg/day† & 21 & 19 \\
\hline Other regimen used elsewhereł & Treatment duration in days & $\begin{array}{l}\text { Medicine cost in US\$* for } 35 \mathrm{~kg} \\
\text { patient } \emptyset\end{array}$ \\
\hline LAMB $10 \mathrm{mg} / \mathrm{kg}$ & 1 & 113 \\
\hline MF 100 mg/day & 28 & $114-160 \S$ \\
\hline LAMB 5 mg/kg+MF 100 mg/day & 8 & 103 \\
\hline LAMB 5 mg/kg+PM 15 mg/kg/day & 11 & 67 \\
\hline MF $100 \mathrm{mg} /$ day+PM $15 \mathrm{mg} / \mathrm{kg} /$ day & 10 & 73 \\
\hline
\end{tabular}

*Exchange rate through http://www.xe.com on 05 December 2018; an Estimated average weight of an African VL patient.

†Monotherapy not used any more, here provided for comparison.

¥Price of LAMB is based on access price US\$16.25 per $50 \mathrm{mg}$ vial. In reality, AmBisome is now provided by donation which started in 2011 through WHO until 2021.

§Price quoted by Knight Therapeutics for purchase by non-profit organisations MSF.

Il Estimated average weight of a VL patient from Africa

LAMB, liposomal amphotericin B; MF, miltefosine; MSF, Médecins Sans Frontières; PM, paromomycin; SSG, sodium stibogluconate.

programmes as they depend on external grants and donor's performance requirements.

The price of VL medicines and diagnostics was stated as one of the principal barriers to ensuring access for all those in need. WHO has established a Long-Term Agreement with most of the manufacturers, essentially an 'advanced commitment' to purchase for an agreed time frame and price. These dialogue between supplier and purchaser includes negotiations to ensure that the price for public health needs remains reasonable; for instance, with Gilead for the access price of AmBisome (table 1) and also with Albert David for SSG. The price of VL medicines, in general, has been increasing and there are no other binding agreements to make sure that these medicines remain affordable. Respondents from $\mathrm{MoH}$ voiced concern over the substantial cost borne by the national programme for the provision of VL diagnostics and treatments without external support (see tables 4 and 5). Eastern Africa needs US $\$ 750000$ to ensure first-line treatment for 15000 patients per year (average US $\$ 50$ per patient).

Communication and coordination barriers to ensuring the supply of VL commodities

Improvement in coordination, collaboration and communication has been reported by participants,

Table 5 Overview of rapid diagnostic tests for visceral leishmaniasis in eastern Africa

\begin{tabular}{|c|c|c|c|c|c|c|}
\hline Product & Manufacturer & Type & $\begin{array}{l}\text { Lateral flow } \\
\text { format }\end{array}$ & Shelf life & $\begin{array}{l}\text { Accuracy in eastern } \\
\text { Africa* }^{*}\end{array}$ & Cost \\
\hline \multicolumn{7}{|l|}{ Tests currently in use } \\
\hline DiaMed-IT LEISH & BioRad Laboratories & RDT rK39 & Cassette & $16 \mathrm{mo}$ & Se $87.2 \%$; Sp $96.4 \%$ & $\begin{array}{l}57.24 \text { Eur } \\
\text { for } 24 \text { kits }\end{array}$ \\
\hline Signal KA & Span Diagnostics, India & RDT rKE16 & Cassette & $12 \mathrm{mo}$ & Se $73.2 \%$; Sp 96.4\% & NA \\
\hline $\begin{array}{l}\text { Onsite Leishmania } \\
\text { Ab Rapid Test }\end{array}$ & CTK Biotech, USA & RDT rKE16 & Dipstick & $18 \mathrm{mo}$ & NA & NA \\
\hline rK28 & CTK Biotech, USA & RDT rK28 & Cassette & NA & Se 92.5\%; Sp 100\%† & US\$3‡ \\
\hline
\end{tabular}

*Source: Cunningham et al. ${ }^{22}$

†Source: Mukhtar et a/ ${ }^{2}$

$\ddagger$ Price quoted for RUO without negotiation.

NA, not available; RDT, rapid diagnostic test; RUO, research use only; Se, sensitivity; Sp, specificity. 
despite examples of misunderstandings and conflicting internal requirements across stakeholders. The small network of individuals and organisations working with VL in the endemic countries enables communication and quick fixes to arising supply issue; borrowing and lending to stopgap stock rupture. The respondents stated that communication is essential to an effective supply chain management and thus should be prioritised.

\begin{abstract}
"You have all kinds of matters influencing the solution of what, again in my eyes, is very simple as we are talking only about a few drugs. We are talking about a disease that is being well-monitored so you could react quite quickly if you had a centralised approach. So the moment you chose not to do that, that is the core issue. You fragment the demand, and you fragment the supply, and that makes it very difficult, and again, it is something we cause ourselves. If for some reason we're not wise enough to step out of whatever problem we have and look for a solution. Again, I'm not naive, but in this case, I find it very difficult to accept that you cannot find a supply solution."(IDI, Implementing NGOs).
\end{abstract}

\section{Perceived remedies to supply chain barriers}

Most respondents mentioned the concept of 'pooled procurement' as an obvious solution, in which countries or purchasers within countries share their needs and make a consolidated forecast for VL procurement.

A pooled procurement with one party responsible for contact, supply and procure the products, keep them in stock and that everybody buys from them would be ideal (IDI, Procurement agency).

However, beyond 'pooling the needs', there are few concrete suggestions from the respondents as to how to move beyond that, for example, combining purchases or negotiations with manufacturers. However, due to the small VL market size, economies of scale would not lead to better prices. For stock management, the web-based District Health Information System 2 is recognised by most stakeholders as a prominent tool, currently being rolled out in all VL endemic countries in eastern Africa by WHO and also for the global emergency stock to which some 50 users worldwide have been granted access. Initially designed as a surveillance tool, this digital platform enables the addition of a leishmaniasis supply dashboard. If filled in correctly it would allow an accurate follow-up of the stock level of medicines and diagnostics at each VL health facility. There is a healthy cautionary attitude towards it, with some respondents endorsing the idea and the tool but questioning the capacity in-country and efforts required to reach the standard. In addition to VL national guidelines, 'standard operating procedures' for the VL supply chain were proposed as guidance for stakeholders, which would be of particular use when personnel change.

Respondents described several current initiatives and commitment to improving access to VL commodities. A global security stock of VL medicines and diagnostics, in essence, a rotating buffer stock, was re-established in 2017 by WHO through an agreement with one of MSF procurement agencies (MSF Logistics in Bordeaux, France). The KalaCORE consortium programme in Africa also implemented a security stock, stored by one of the procurement agencies, IDA Foundation, in 2015-2016. VL endemic countries may use the WHO emergency stock to cover the treatment of 1000 patients immediately. However, with a limited 5-year funding guarantee for the WHO leishmaniasis programme, there is an uncertainty about this approach in the long run, despite a clear consensus among stakeholders on its purpose, benefits and scope. The IDA Foundation in Amsterdam has committed to ensuring the continued availability of SSG and PM; through working with the manufacturers on quality assurance and control, keeping stocks in Amsterdam for immediate shipment, and taking responsibility for the registration of both drugs in East African countries, while DND $i$ facilitated their registration financially. These collaborations need to be fostered and maintained-the AmBisome donation programme through WHO is a positive development, although the sustainability beyond 2021 is not ensured.

\begin{abstract}
"WHO is getting the donations and there's a contract they signed with the manufacturer. Unfortunately, it's very short-sighted and without condition to the manufacturers, such to engage in registration, affordable price... it needs to happen. It's one thing to have the donation, but we often see that the donation is not enough or that the donation needs to pave the way for the future." (IDI, NGOs).
\end{abstract}

In this regard, all respondents emphasised that longterm solutions can only be achieved if they come from the country itself and are not (wholly driven) by external partners. A regional approach to this common problem was an attractive idea for most of the stakeholders, mirroring the commitment for VL elimination in the Indian subcontinent. Nevertheless, the respondents also noted that the context in each country needs to be considered; South Sudan and Somalia are still in armed conflict, whereas Sudan, Ethiopia, Kenya and Uganda also differ regarding capacity and resources that are available for VL and NTDs in general. Securing political commitment seems crucial for securing the resources needed to maintain progress. Integration with the in-country supply of essential medicines is heavily questioned by the study respondents, mostly in terms of justification and feasibility. To some, the low number of commodities and the low quantities involved are good reasons for integrating VL supply, whereas those convinced that the neglect of this disease will persist, argue that a dedicated and separate supply channel is still the only way to go. The integration of small amounts of donated drugs into the regular supply chain was not deemed even necessary.

\section{DISCUSSION}

This study expounds on barriers identified by the representatives of the primary stakeholders at the global and 
national levels in the VL supply chain in eastern Africa that need to be addressed to increase access to diagnosis and treatment. These barriers were grouped into supply chain activities and health system, while fully recognising that they are inter-related and interdependent. The bottlenecks affect medicines and diagnostics, whose availability and access are imperative for VL case detection and management. For the patients, these medicines and diagnostics are life-saving; and from the public health perspective, VL control is impossible without them. Physicians, other field health staff and overall health system certainly benefit from an uninterrupted supply of VL medicines and diagnostics.

The eastern Africa region bears the highest burden of VL cases worldwide, yet VL supply chain management is still based mainly on parallel and externally supported efforts. The short list of VL medicines and diagnostics do not mean that their availability and access are secured. The barriers described by study respondents demonstrate a range of issues at global, national and subnational levels. There is no real 'selection' or competition of sources of VL medicines and diagnostics for supply, as for most items a single manufacturer only produces the product, that is, generic SSG, PM, MF and AmBisome. Another antimonial, MA (Glucantime), has never been used widely in eastern Africa except as a substitute when SSG is not available. Therefore, the default choice remains $\mathrm{SSG} / \mathrm{PM}$ as recommended in the six countries as first-line treatment. The fact that the supplier pool has not expanded puts a real critical risk if production ceases. Though all VL medicines are included in the WHO Model of Essential Medicines List, there is a lack of WHO prequalified sources. This problem has been mitigated through the WHO Expert Review Panel assessments of SSG and PM, but manufacturers should be more engaged in adequate procedures to ease procurement in the future (eg, properly registered, aiming for pre-qualification), and purchasers could join forces to jointly require that manufacturers implement stringent quality assurance (ie, WHO PreQualification Programme).

Affordability is still a significant issue: VL medicines and diagnostics are still relatively expensive from the national perspective, despite price reductions negotiated by WHO or at cost price with a negligible profit margin. ${ }^{41}{ }^{42}$ Companies do not always register medicines with preferential prices where they are needed, as there is no profitable market. ${ }^{43}$ Not all medicines in the national treatment protocols are available in endemic countries, even though they are included in the national essential drug lists. ${ }^{44} \mathrm{VL}$ medicines, except AmBisome, have no other substantial indication outside leishmaniasis and significant global case reduction in the Indian subcontinent have shrunk the market volume for $\mathrm{VL},{ }^{45}$ whereas cutaneous leishmaniasis (CL) now represents a larger market for these drugs, as well as HIV/VL co-infection and post-kala-azar dermal leishmaniasis. In reality, despite the designation of VL medicines for patients with VL, patients with CL also are being treated and contribute to increased demand, for example, in Sudan or Ethiopia. ${ }^{45}$ As these drugs are mainly procured through public or non-for-profit channels, competition from new producers is unlikely in the short term. ${ }^{46}$ The current preferential pricing (for MF and $\mathrm{PM}$ ) and donation programme (for AmBisome) ${ }^{47}$ are not long-term solutions, although they are acceptable for VL (no multisource production capacity and small market size) ${ }^{48-50}$ Alternate strategies are needed to achieve the lowest sustainable price, that is, a price that fulfils the criteria of affordability aligning with public health needs while keeping production a viable option before new drugs enter the market. ${ }^{12}$

Our findings indicatethat the importance of diagnostics has been underestimated. All barriers related to the VL medicines supply chain inevitably affect VL diagnostics, mainly rK39 RDTs. Despite the suboptimal performance of RDT and worse for patients with VL/HIV, 22 51-53 RDTs remain valuable for eastern Africa contexts, where delays in diagnosis remain an unaddressed needs. ${ }^{27} 54$ Unfortunately, in eastern Africa, not all brands of rK39 RDTs perform equally well and improved field-adjusted diagnostic tool is urgently needed..$^{2255}$

Recent collaborative efforts across stakeholders groups have led to improved coordination and consensus to address access issues better, creating a window of opportunity. ${ }^{56}$ Taking stocks on what has been tried and learnt in the last decade and proposing ways forward has implications at various levels. A common platform of VL drug supply monitoring could facilitate better forecasting and needs' estimation. The establishment of rotating buffer stock and centralisation of procurements were seen as low hanging fruits. ${ }^{57}$ Centralised procurement reduces $\operatorname{cost}^{58}$ and consolidating demand in a "pooled procurement' process appears attractive especially as the number of products is few. ${ }^{57}$ Nevertheless, there are central design issues to be considered, such as ownership (governments or regional/international quasi-government organisations) and mechanisms. Several 'models' exist and could provide insights into similar schemes for VL in eastern Africa, for example, the centralised supply mechanism for the human African trypanosomiasis medicine donation programme, the International Crisis Group (for vaccines), the Drug Revolving Fund of the WHO American Region (Pan American Health Organization), the Tuberculosis Global Drug Facility and the Gulf Cooperation Council Group Purchasing Program. ${ }^{57} 59$ Each has advantages and limitations. Therefore, in-depth scrutiny of these mechanisms in a feasibility study is needed. The regional approach, however, is desirable.

At the global level, although advocacy efforts have increased VL awareness nationally and internationally, the sustainability remains compromised. Respondents liken the current situation to plastering over the cracks rather than addressing the root causes, which would require a real political commitment and allocation of domestic resources. VL programmes could benefit from cross-cutting health system strengthening efforts, such as financing mechanisms, information system and legislation, ${ }^{36}$ but 
Table 6 Summary of barriers and action recommendations for the visceral leishmaniasis supply chain in eastern Africa

\begin{tabular}{|c|c|c|}
\hline Area & Barriers & $\begin{array}{l}\text { Recommended actions with level of actions required } \\
\text { (global, regional or national) }\end{array}$ \\
\hline \multicolumn{3}{|l|}{ Specific areas } \\
\hline Forecast/procurement & $\begin{array}{l}\text { Lack of adequate stock } \\
\text { management } \\
\text { Difficulty in forecasting }\end{array}$ & $\begin{array}{l}\text { Accelerate use and roll out of common tool (DHIS2) - } \\
\text { regional, national } \\
\text { Engage in defining and using 'pooled forecast and } \\
\text { procurement' alongside existing mechanisms - regional } \\
\text { Clarify and harmonise in-country procurement procedures - } \\
\text { regional and national }\end{array}$ \\
\hline Distribution & $\begin{array}{l}\text { Logistical challenges } \\
\text { Parallel vertical channels }\end{array}$ & $\begin{array}{l}\text { Maintain the WHO-led 'emergency stock' and explore } \\
\text { alternatives for medium and long-term - global and } \\
\text { regional } \\
\text { Examine the feasibility of integration with essential } \\
\text { medicine supply - all }\end{array}$ \\
\hline \multicolumn{3}{|l|}{ Cross-cutting } \\
\hline Regulatory & $\begin{array}{l}\text { Registration in all endemic } \\
\text { countries } \\
\text { Pathways for RDT registration } \\
\text { and use }\end{array}$ & $\begin{array}{l}\text { Harmonisation of regulatory standards, including for RDTs } \\
\text { - all } \\
\text { Support and (market) incentives for WHO PQP for VL } \\
\text { products - global } \\
\text { Share and communicate between regulatory authority, } \\
\text { control programmes, partners, manufacturers and other } \\
\text { stakeholders - global }\end{array}$ \\
\hline Financing & $\begin{array}{l}\text { Still relatively expensive } \\
\text { Sustainability }\end{array}$ & $\begin{array}{l}\text { Safeguard public health price through negotiations and } \\
\text { binding agreements - global } \\
\text { Ensure VL care included in national budget and UHC } \\
\text { benefit package - national } \\
\text { Define strategy to ensure sustainability of VL supply with a } \\
\text { regional approach - regional }\end{array}$ \\
\hline
\end{tabular}

DHIS2, District Health Information System; PQP, PreQualification Programme; RDT, rapid diagnostic test; SOP, standard operating procedure; UHC, universal health coverage; VL, visceral leishmaniasis.

also targeted projects on pharmaceutical supply management and access to medicines in general. ${ }^{6061}$ Empowering country staff is paramount to achieving country ownership and responsibility towards patients with VL in the long run. Table 6 summarises our recommended actions from the public health perspective.

\section{What are the implications for policy and research?}

Despite the gargantuan task of addressing these barriers, clear mapping can help prioritise actions and inform future activities and intervention. Policy-makers, programme managers, academics and suppliers should work better together to investigate which type of actions is relevant in which type of context, across the six VL endemic countries. A good level of communication across stakeholders needs to be nurtured and strengthened to develop a collective bargaining power in securing access. Unlike the case for HIV/AIDS or TB, patients with VL are less vocal in expressing their demands, and mostly do not influence international or national priority setting. Strategies for a wide dissemination of the study findings through policy brief and advocacy efforts are therefore requisite.

Future research should help better monitoring of access to quality-assured antileishmanial medicines and diagnostics, taking into account the specific context in these endemic countries. An efficient and effective supply 
chain should not be seen as a merely technical and organisational challenge; the socioeconomic deprivation of the affected communities should be acknowledged as having a profound link. Simultaneous actions to strengthen health systems and to overcome these barriers are critical, considering the time required for new, better medicines and diagnostics for VL in eastern Africa to become a reality.

\section{CONCLUSION}

This study aimed to better understand the key barriers and enablers for an efficient, effective supply chain for VL medicinesand diagnostics in the eastern Africa region. Ensuring a reliable supply chain for VL has been chronically challenging due to the context and dependence on external support. This study provides clear documentation of key barriers along the supply chain for VL medicines and diagnostics. Addressing these barriers calls for a more unified approach among the stakeholders. Our findings indicate that despite the diversity in each country's context, simultaneous efforts and collaboration in policy and implementation are required. At the country level, national interagency technical working groups to drive the VL agenda appears to be needed. Regional coordination for forecasting and procurement is synchronised with global leadership through a partnership of stakeholders and funders on pricing and availability. Although perspectives may differ, the ultimate goal of increasing access to VL care should guide actions and collaborations in the future.

\section{Author affiliations}

${ }^{1}$ Public Health Department, Institute of Tropical Medicine, Antwerpen, Belgium ${ }^{2}$ Medical Department, Médecins Sans Frontières Access Campaign, Paris, France ${ }^{3}$ Medical Department, Artsen zonder Grenzen, Amsterdam, The Netherlands ${ }^{4}$ Neglected Tropical Diseases Programme, World Health Organization, Geneva, Switzerland

${ }^{5}$ VL Clinical Program, Drugs for Neglected Disease Initiative, Geneva, Switzerland

${ }^{6}$ Instituto de Salud Global Barcelona, Barcelona, Spain

${ }^{7}$ Neglected Tropical Diseases Department, FIND, Geneva, Switzerland

Acknowledgements The authors want to thank all the respondents willing to take part in the study. All members of the WHO Working Group on Access to Leishmaniasis have been crucial in shaping the study since its conception. They thank Ellen van Asselbergh for her transcribing assistance.

Contributors TS, JP and MB: conceptualised the study. JP, MdB, KR, FA, JARP, RR, AP and MB: data collection, assessment and interpretation. TS: collected, analysed the data and wrote the first draft. All authors critically reviewed and approved the final manuscript. MB and AP: obtained the funding. MB is the guarantor of the study.

Funding This project has received funding from the European Union's Horizon 2020 research and innovation programme under the Marie Sklodowska-Curie grant agreement № 642609.

Competing interests RR was a member of the EuroLeish Ethics Board and ITM IRB. As such, she participated in the ethics review of this project, before she became involved in the assessment and interpretation of these findings. MdB, JP and KR are affiliated with Médecins Sans Frontieres (MSF), which has been actively working in the field of leishmaniasis in Africa since decades. MSF is currently running VL projects in Ethiopia, Sudan, and South Sudan. FA is affiliated to DNDi, an organization dedicated to develop new treatment for neglected diseases, with VL as one of the focus. DNDi manages treatment centers in Sudan, Kenya and Uganda. JARP is affiliated to WHO Geneva in the Leishmaniasis program and have been involved in technical support to the countries for the VL control globally. WHO also hosted the WHO Working Group on Access to Leishmaniasis medicines where MSF and DNDi were active participants.

Patient consent for publication Not required.

Provenance and peer review Not commissioned; externally peer reviewed.

Data sharing statement The data supporting the conclusion of this article are available upon request to the corresponding author. The original data contain information which may lead to the identification of study participants and to protect their privacy. We will not make participants data publicly available.

Open access This is an open access article distributed in accordance with the Creative Commons Attribution Non Commercial (CC BY-NC 4.0) license, which permits others to distribute, remix, adapt, build upon this work non-commercially, and license their derivative works on different terms, provided the original work is properly cited, appropriate credit is given, any changes made indicated, and the use is non-commercial. See: http://creativecommons.org/licenses/by-nc/4.0/.

\section{REFERENCES}

1. Trouiller P, Olliaro P, Torreele E, et al. Drug development for neglected diseases: a deficient market and a public-health policy failure. Lancet 2002;359:2188-94

2. Pedrique B, Strub-Wourgaft N, Some C, et al. The drug and vaccine landscape for neglected diseases (2000-11): a systematic assessment. Lancet Glob Health 2013;1:371-9.

3. Pécoul B, Chirac P, Trouiller P, et al. Access to essential drugs in poor countries: a lost battle? JAMA 1999;281:361-7.

4. World Health Organisation. Global leishmaniasis surveillance update, 1998-2016. Wkly Epidemiol Rec 2018;40:521-40.

5. WHO. Leishmaniasis in high-burden countries: an epidemiological update based on data reported in 2014. Wkly Epidemiol Rec 2016;91:287-96.

6. Al-Salem W, Herricks JR, Hotez PJ. A review of visceral leishmaniasis during the conflict in South Sudan and the consequences for East African countries. Parasit Vectors 2016;9:460.

7. Abubakar A, Ruiz-Postigo JA, Pita J, et al. Visceral leishmaniasis outbreak in South Sudan 2009-2012: epidemiological assessment and impact of a multisectoral response. PLoS Negl Trop Dis 2014;8:2012-5.

8. Seaman J, Mercer AJ, Sondorp E. The epidemic of visceral leishmaniasis in western Upper Nile, southern Sudan: course and impact from 1984 to 1994. Int J Epidemiol 1996;25:862-71.

9. Meheus F, Abuzaid AA, Baltussen R, et al. The economic burden of visceral leishmaniasis in Sudan: an assessment of provider and household costs. Am J Trop Med Hyg 2013;89:1146-53.

10. Boelaert M, Meheus F, Sanchez A, et al. The poorest of the poor: a poverty appraisal of households affected by visceral leishmaniasis in Bihar, India. Trop Med Int Health 2009;14:639-44.

11. Mondal D, Singh SP, Kumar N, et al. Visceral leishmaniasis elimination programme in India, Bangladesh, and Nepal: reshaping the case finding/case management strategy. PLoS Negl Trop Dis 2009;3:e355.

12. Alves F, Bilbe G, Blesson S, et al. Recent Development of Visceral Leishmaniasis Treatments: Successes, Pitfalls, and Perspectives. Clin Microbiol Rev 2018;31:e00048-18.

13. van Griensven J, Balasegaram M, Meheus F, et al. Combination therapy for visceral leishmaniasis. Lancet Infect Dis 2010;10:184-94.

14. World Health Organization. Control of the leishmaniases: Report of a meeting of the WHO Expert Committee on the Control of Leishmaniases, Geneva, 22-26 March 2010. Geneva: World Health Organ Tech Rep Ser, 2010:186.

15. Musa A, Khalil E, Hailu A, et al. Sodium stibogluconate (SSG) \& paromomycin combination compared to SSG for visceral leishmaniasis in East Africa: a randomised controlled trial. PLoS Negl Trop Dis 2012;6.

16. Seaman J, Mercer AJ, Sondorp HE, et al. Epidemic visceral leishmaniasis in southern Sudan: treatment of severely debilitated patients under wartime conditions and with limited resources. Ann Intern Med 1996;124:664-72.

17. Chappuis F, Alirol E, Worku DT, et al. High mortality among older patients treated with pentavalent antimonials for visceral leishmaniasis in East Africa and rationale for switch to liposomal amphotericin B. Antimicrob Agents Chemother 2011;55:455-6.

18. Salih NA, van Griensven J, Chappuis F, et al. Liposomal amphotericin B for complicated visceral leishmaniasis (kala-azar) in eastern Sudan: how effective is treatment for this neglected disease? Trop Med Int Health 2014;19:146-52. 
19. ter Horst R, Collin SM, Ritmeijer K, et al. Concordant HIV infection and visceral leishmaniasis in Ethiopia: the influence of antiretroviral treatment and other factors on outcome. Clin Infect Dis 2008:46:1702-9.

20. Khalil EA, Weldegebreal T, Younis BM, et al. Safety and efficacy of single dose versus multiple doses of AmBisome for treatment of visceral leishmaniasis in eastern Africa: a randomised trial. PLOS Negl Trop Dis 2014;8:e2613.

21. Wasunna M, Njenga S, Balasegaram M, et al. Efficacy and Safety of AmBisome in Combination with Sodium Stibogluconate or Miltefosine and Miltefosine Monotherapy for African Visceral Leishmaniasis: Phase II Randomized Trial. PLoS Negl Trop Dis 2016;10:1-18.

22. Cunningham J, Hasker E, Das P, et al. A global comparative evaluation of commercial immunochromatographic rapid diagnostic tests for visceral leishmaniasis. Clin Infect Dis 2012;55:1312-9.

23. Boelaert M, Verdonck K, Menten J, et al. Rapid tests for the diagnosis of visceral leishmaniasis in patients with suspected disease (Review) Rapid tests for the diagnosis of visceral leishmaniasis in patients with suspected disease. Cochran Libr 2014;6:2-4.

24. den Boer M, Argaw D, Jannin J, et al. Leishmaniasis impact and treatment access. Clin Microbiol Infect 2011;17:1471-7.

25. KalaCORE. Visceral leishmaniasis treatment access - the reality on the ground in Sudan. WorldLeish6, 2017.

26. Sunyoto T, Adam GK, Atia AM, et al. "kala-Azar is a Dishonest Disease": Community perspectives on access barriers to visceral leishmaniasis (Kala-Azar) diagnosis and care in Southern Gadarif, Sudan. Am J Trop Med Hyg 2018;98:1091-101.

27. Coulborn RM, Gebrehiwot TG, Schneider M, et al. Barriers to access to visceral leishmaniasis diagnosis and care among seasonal mobile workers in Western Tigray, Northern Ethiopia: A qualitative study. PLoS Negl Trop Dis 2018;12:e0006778.

28. Nurse-Findlay S, Taylor MM, Savage M, et al. Shortages of benzathine penicillin for prevention of mother-to-child transmission of syphilis: An evaluation from multi-country surveys and stakeholder interviews. PLoS Med 2017:14:1-18.

29. Schouten EJ, Jahn A, Ben-Smith A, et al. Antiretroviral drug supply challenges in the era of scaling up ART in Malawi. J Int AIDS Soc 2011;14(SUPPL. 1):1-8.

30. Matowe L, Waako P, Adome RO, et al. A strategy to improve skills in pharmaceutical supply management in East Africa: the regional technical resource collaboration for pharmaceutical management. Hum Resour Health 2008:6:1-6.

31. Koporc KM, Strunz E, Holloway C, et al. Assessing "First Mile" Supply Chain Factors Affecting Timeliness of School-Based Deworming Interventions: Supply and Logistics Performance Indicators. PLoS Negl Trop Dis 2015;9:1-10.

32. Lin WM, Addiss DG. Sustainable access to deworming drugs in a changing landscape. Lancet Infect Dis 2018;18:395-8.

33. Frost LJ, Reich MR. Creating access to health technologies in poor countries. Health Aff 2009;28:962-73.

34. Reich MR, Frost LJ. Research Studies for Promoting Access to Health Technologies in Poor Countries. Access 2010(June):28-30.

35. Bigdeli M, Jacobs B, Tomson G, et al. Access to medicines from a health system perspective. Health Policy Plan 2013;28:692-704.

36. Yadav P. Health Product Supply Chains in Developing Countries: Diagnosis of the Root Causes of Underperformance and an Agenda for Reform. Heal Syst Reform 2015;1:142-54.

37. Ritchie J, Lewis J. Qualitative research practice: a guide for social science students and researchers. London: Sage, 2003.

38. Gale NK, Heath G, Cameron E, et al. Using the framework method for the analysis of qualitative data in multi-disciplinary health research. BMC Med Res Methodol. BioMed Central 2013;13:117.

39. Braun V, Clarke V. What can "thematic analysis" offer health and wellbeing researchers? Int J Qual Stud Health Well-being. Taylor \& Francis 2014;9:26152.

40. Braun V, Clarke V. Using thematic analysis in psychology. Qual Res Psychol 2006;3:77-101.
41. Thornton SJ, Wasan KM, Piecuch A, et al. Barriers to treatment for visceral leishmaniasis in hyperendemic areas: India, Bangladesh, Nepal, Brazil and Sudan. Drug Dev Ind Pharm 2010;36:1312-9.

42. Sunyoto $T$, Potet $J$, Boelaert $M$. Why miltefosine-a life-saving drug for leishmaniasis-is unavailable to people who need it the most. $B M$ Glob Health 2018;3:e000709.

43. Wellcome B WHO, Wasunna M, Njenga S, et al. Registering New Drugs : The African Context. Clin Infect Dis 2012;100:785-91.

44. Moran M, Strub-Wourgaft N, Guzman J, et al. Registering new drugs for low-income countries: the African challenge. PLoS Med 2011;8:8-13

45. World Health Organization. WHO bi-regional consultation on the status of implementation of leishmaniasis control strategies and epidemiological situations in Eastern Africa. Addis Ababa, 2018.

46. Gaspani S. Access to liposomal generic formulations: beyond AmBisome and Doxil/Caelyx. Generics Biosimilars Initiat $J$ 2013;2:60-2

47. WHO. WHO and Gilead sign agreement for enhanced access to visceral leishmaniasis treatment [Internet]. 2011 http://www.who.int/ neglected_diseases/Gilead_donation_2011/en/ (cited 2018 Sep 17)

48. Pérez-Casas C, Herranz E, Ford N. Pricing of drugs and donations: options for sustainable equity pricing. Trop Med Int Health 2001;6:960-4.

49. Moon S, Jambert E, Childs M, et al. A win-win solution?: A critical analysis of tiered pricing to improve access to medicines in developing countries. Global Health 2011;7:39.

50. Moon S, Bermudez J, 't Hoen E. Innovation and access to medicines for neglected populations: could a treaty address a broken pharmaceutical R\&D system? PLoS Med 2012;9.

51. Boelaert M, Verdonck K, Menten J, et al. Rapid tests for the diagnosis of visceral leishmaniasis in patients with suspected disease. Cochrane database Syst Rev 2014;6.

52. Chappuis F, Rijal S, Soto A, et al. A meta-analysis of the diagnostic performance of the direct agglutination test and rK39 dipstick for visceral leishmaniasis. BMJ 2006;333:723-6.

53. van Griensven J, Diro E, Lopez-Velez R, et al. A screen-and-treat strategy targeting visceral leishmaniasis in HIV-infected individuals in endemic East African countries: the way forward? PLoS Negl Trop Dis 2014;8.

54. Sunyoto T, Adam GK, Atia AM, et al. "Kala-Azar is a Dishonest Disease": Community Perspectives on Access Barriers to Visceral Leishmaniasis (Kala-Azar) Diagnosis and Care in Southern Gadarif, Sudan. Am J Trop Med Hyg 2018;98.

55. Makoni M. Boosting quality diagnostics could give Africa better health. Lancet 2018;392:2426.

56. WHO. WHO |WHO aims to improve access to antileishmanial medicines in affected countries: WHO. World Health Organization, 2016.

57. Huff-Rousselle M. The logical underpinnings and benefits of pooled pharmaceutical procurement: a pragmatic role for our public institutions? Soc Sci Med 2012;75:1572-80.

58. Seidman G, Atun R. Do changes to supply chains and procurement processes yield cost savings and improve availability of pharmaceuticals, vaccines or health products? A systematic review of evidence from low-income and middle-income countries. BMJ Glob Health 2017;2:e000243.

59. DeRoeck D, Bawazir SA, Carrasco P, et al. Regional group purchasing of vaccines: review of the Pan American Health Organization EPI revolving fund and the Gulf Cooperation Council group purchasing program. Int $J$ Health Plann Manage 2006;21:23-43

60. Management Sciences for Health. Toward Building Resilient Pharmaceutical Systems: SIAPS Final Report. Arlington, 2017.

61. Wirtz VJ, Hogerzeil HV, Gray AL, et al. Essential medicines for universal health coverage. Lancet 2017;389:403-76.

62. Mukhtar M, Abdoun A, Ahmed AE, et al. Diagnostic accuracy of rK28-based immunochromatographic rapid diagnostic tests for visceral leishmaniasis: a prospective clinical cohort study in Sudan. Trans R Soc Trop Med Hyg 2015;109:594-600. 